\title{
Effects of Electronic Register on Teachers Absenteeism in Osadenis mixed Secondary School Delta State, Nigeria
}

\author{
Uchechukwu Anthony Nwobi Ph.D. ${ }^{1}$ Okolie, C. Anthony Ph.D. ${ }^{2}$ \\ \& Fidelis C. Nwagbara. ${ }^{3}$
}

\author{
${ }^{1}$ Department of Public Administration, NOUN \\ 2 Department of Public Administration \& Local Government, UNN. \\ ${ }^{3}$ Doctoral fellow: Department of Public Administration \& Local Government, UNN. \\ ucheanwobi@gmail.com, anthony.okolie@unn.edu.ng, \\ fidelischijioke@gmail.com.
}

\section{Received: 11.02.2020 Accepted: 20.04.2020 \\ Date of Publication: June, 2020}

\begin{abstract}
The study was on electronic register and teachers' absenteeism. The objective of the study was to examine the effects of electronic register on teachers' absenteeism in Osadenis mixed secondary school Delta state, Nigeria. Specifically, the study ascertained if the use of electronic register has helped in reducing teachers' absenteeism to work in Osadenis mixed secondary school Delta state, Nigeria. The study was a survey research. Simple random sampling procedure was used. The primary and secondary sources of data were employed. Behavioural change theory was adopted. The findings revealed that the use of electronic register has reduced teachers' absenteeism from work. Other findings showed that ghost workers no longer find it easy because of the use of thump print during clocking-in and clocking-out of work. It has helped to enforce punctuality. Based on the findings, the following recommendations were made. There should be a reasonable deduction on the salary of any teacher who absent from work without an acceptable reason and permission from the management. There should be improvement on the function of the machine via provision of constant light and trained experts to manage and maintain the device.
\end{abstract}

Keywords: Electronic register, teacher, absenteeism, school and Delta State. 


\section{Introduction}

Electronic register is a biometric time clock system that monitors employees clock-in and clock-out for work using verification technique such as fingerprints, retinal scanning, or even facial recognition scanning with extremely precise software recording time $\operatorname{logs}$ and verifying employee attendance in order to ensure that the employees are who they say they are. In the light of the above, the use of biometry such as laptops, mobile phones and other technologies has become a meaningful tool in managing employees of institutions, (Mikhaylov 2019). This is because absence from work has generally been on the increase even though many organizations have put in place positive changes in their bold attempts to reduce the incidence of absenteeism, (Ugoani 2016). Similarly, an absentee is a teacher or worker who is expected to be in a particular place such as workplace at a particular time but is not there, (Ejere 2010).

In the same vein, one of the daunting challenges of employers is time and attendance clock fraud. This implies when workers sign in and out for hours or days they did not work or sign in and out other employees who aren't actually at work. Besides, there has been an increasing high rate of teachers' absenteeism to work leading to disruption and ineffective instruction to students. This has become a nuisance in the workplace and unnecessary cost to productivity, (Ivory 2016). Beyond that incidence, some of the teachers absent themselves from work for several reasons such as: personal reasons, personal illness, family responsibility, personal business, work place abuse, poor supervision of the principal, extracurricular activities, high work load, poor control of the principal, job dissatisfaction and death in the family. Amidst that, the teachers who absent themselves from work, often claim to be suffering from various illnesses, when ordinarily, they have simply chosen to opt out of work rather than opting in. They take advantage of poor supervision of attendance to absent themselves from work without genuine reasons. Others get involved on things outside the scope of work as pretence to absent from work, (Robinson 2008).

Worthy of note is that, overtime there has been a serious struggle or battle on the strategies that could be used to curtail this daunting time fraud. To address the restiveness, the automated machine for clocking-in and clockingout of work for teachers was introduced to eliminate time larceny, increase security, The Citizen Newspaper (2018) enhance effective, accurate and timely record keeping for the workers and monitor the attendance of teachers at work, (Jethro-Ibileke 2017).

\section{Statement of the Problem}

The contention was anchored on workers' absenteeism and how to tame the tide. There were challenges of ineffective instruction to students, time larceny, attendance fraud, low productivity and insecurity. Furthermore, there was wasteful organizational practice, waste of fund, truancy, and reduction in employment opportunities. Some of those problems led to the curiosity to provide answers to the following question:

\section{Research Question}

1. Does the use of electronic register help to reduce teachers' absenteeism to work in Osadenis mixed secondary school Delta state, Nigeria?

\section{Objective of the Study}

The general objective is to examine the effects of electronic register on teachers' absenteeism in Osadenis 
mixed secondary school Delta state, Nigeria. Specifically the study was to:

1. Ascertain if the use of electronic register has helped in reducing teachers' absenteeism to work in Osadenis mixed secondary school Delta state, Nigeria.

\section{Review of Related Literature}

The literature in this study was reviewed under the following sub-themes:

- Electronic Register

- Teacher

- Absenteeism

- A Trajectory of Electronic Register for Workers' in Delta State

- Empirical Review

- Gap in Literature

\section{Electronic Register}

Electronic register is a data storage device that is more sophisticated than latches. Electronic register is a group of binary cells suitable for holding binary information. A group of cascaded flipflops used to store related bits of information is known as a register, (Wikibooks 2017). Is a device that processes data and store record of somebody, something on an official list or data base, (Hornby 2015). In a nut shell, electronic register is a device that stores the bio data of a teacher with a provision for a thump print when clocking in and clocking out of work in order to monitor attendance of teachers accurately and timely.

\section{Teacher}

It means a person whose job is teaching. It could be in a church, home but most especially in schools, (Hornby 2015). In the same perspective, a teacher is someone who contributes to the growth of others who has the quality of love of knowledge and a love of contributing to the development of others, (Waldron 2008). In addition, it connotes an expert who has the ability to impart knowledge in order to assist learners to build, identify and to acquire skills that will be used to face the challenges in life. In other words, a learner's development will be enhanced to utilize the available opportunities within the environment towards securing an employment and acquiring adequate skills to fit into the society, (Sende 2000). In a nutshell, a teacher is an individual employed mostly in a school to teach in order to create behavioural change of the learner.

\section{Absenteeism}

Absenteeism is the act of being frequently away from work or school unofficially without permission or good reasons, (Hornby 2015). In the same light, it implies a teacher's absence from regular work when ordinarily he or she is supposed to be at work. In other words, it is the failure of an employee on a pay roll to report to duty against work ethics. It could be as a result of personal reasons, illness, among others whether authorized or not. When it occurs often devoid of notice, it deters productivity in an institution, (Bhatia 1981).

Equally, it connotes unplanned absence or non-attendance at work where work attendance is scheduled. Absenteeism could occur as a result of sickness leave, bereavement leave and may also include time lost through industrial disputes, (Australasian Faculty of Occupational Medicine 1999). In the same perspective, it could mean the failure to report to work. The habit of absenteeism on a regular basis will culminates into a 
threat to productivity of an institution, (Badubi, 2017).

\section{A Trajectory of Electronic Register for Workers' in Delta State}

The brain behind the electronic register for workers' in Delta State is a company called Hekerbella Limited under the democratic dispensation of Governor Ifeanyi Okowa. It is usually on a four years contract. It is an electronic device configured with the use of Itel modeled hand held phone. It has a record of bio data of all staff and stores the last time a worker is seen in the office. The idea of electronic register for workers emanated as a continuation of the ongoing Staff Verification Exercise in Delta State Civil Service. It entails the Clocking-in and clocking-out for Staff of Delta state government. The whole workers are expected to clock in with their thick finger print upon resumption of duty in the morning, after the long break and clock out at the close of work, (Osahor 2017).

The computer device has the tendency of not recognizing the worker if not handled properly. The inefficiency of the electronic device was linked to network fluctuation, (The Citizen Newspaper 2018). The state currently has an electronic staff database (which is available in soft and hard copies to Commissioners, board members and Directors). It captures the official details of staff including their passport photographs and signatures. It is updated as they progress along their career line and as officers are posted in and out of each government ministries and parastatals. The hard copies are verified and signed by the various departmental heads/directors and their claims countersigned by the Permanent Secretary or the Chairman. This is to ensure that every head of department is accountable for his/her staff, thus helping to checkmate the incidence of ghost workers. It reports the regularity and punctuality of staff on a monthly basis by analyzing the number of times a staff came to work and the time he checked in as recorded by the attendance register of each department, which is monitored by the director. The specimen signature captured in the database stands as a check against the possibility of a staff signing for another. It is hoped that this will reduce, if not eradicate the incidence of absenteeism or late coming (The Chairman 2017).

\section{Empirical Review}

Different researchers carried out research on teachers' absenteeism in different parts of the world. One of these studies was conducted in Tanzania by Mgonja (2017) in responding to workplace absenteeism in Tanzania: The case of public and private schools in Ilala Municipal and Mkuranga District, written by Mgonja. The goal was to study the mechanism used to mitigate workplace absenteeism, their adequacy and the effective utilization of those mechanism in public and private schools in Ilala Municipality and Mkuranga District in Tanzania. The study made use of in-depth interviews and documentary review to collect data which was analyzed using excel, content and thematic analysis. The study found out that unlike in private schools, the measures are not seriously executed in public schools. The study recommends that the management of private schools should retain their strictness in dealing 
with teacher absenteeism. Again, public secondary school management structure should be re- organized to introduce field of supervision at a division level. The previous and present studies were similar because they focused on secondary schools while the difference was that the previous study used excel, content and thematic analysis while the present study will use mean scores. However, the title of the paper was 19 words which were very long. Again, the researcher did not use questionnaire to generate more data thus the study was not statistically analyzed. There is a limitation to the applicability of the result of the mechanism used to mitigate absenteeism as mentioned by Mgonja.

In the same vein, the paper titled the anatomy of absenteeism authored by Markussen, Roed, Rogeberg, \& Gaure (2009) was aimed at examining the origins of the observed variation in absenteeism in Norway across time and space. Novel concept of workers steady state sickness absence propensity, computed from a multivariate hazard rate model designed to predict the incidence and duration of sickness absence of all workers was used. The findings revealed that most of the crosssectional variation in absenteeism is caused by genuine employee heterogeneity, the identity of a person's panel doctor has a significant impact on absence propensity and sickness absence insurance is frequently certified for reasons other than sickness, (Markussen, Roed, Rogeberg \& Gaure 2009). The previous study used multivariate hazard rate model while the present study will use simple random sampling method. The population of the study is not known so the researcher does not have a sample. Again, the category of workers was not sown.

Similarly, another study was aimed at exploring with line managers some guidelines for an absenteeism management in the environment of higher learning in order to gain insight from line managers into the variables to be taken into consideration in the development of an absenteeism management programme. The study was qualitative. A non-probability sampling method with purposive sampling for selecting the sample was employed. Data was analyzed using transcribing and interpreting of data. Findings revealed that participants were faced with employees absenteeism in the course of their daily operations, there was lack of proper policies and procedures within the institution to guide them in curtailing absenteeism, (Mogobe 2011). There was no justification for the use of purposive sampling method. The study did not tell us how data was collected in the course of the study. Significant results were noted but the limitation is that the study did not show the way out of those challenges the findings revealed. For instance the proper policies and procedures were not were not highlighted. This lack of details would make it difficult for readers and beneficiaries to know the way forward. Future research in related area will address the challenge.

In another study, the goal was to find out how various factors such as personal factors, school factors and environmental factors contributed to uncontrolled teachers' absenteeism in

\section{URL: http://journals.covenantuniversity.edu.ng/index.php/cjbss}


selected public primary schools in Mangaung metro municipality. Ten (10) school principals, 60 teachers and one human resource personnel from the district office were used. Questionnaire and interview were used. Quantitative and qualitative methods of analysis were used. Findings revealed that there is an urgent need to engage in critical discussion about the various types of leave like study leave, sick leave, family responsibility leave and special leave for urgent private matters. It was revealed that uncontrolled teacher absenteeism affects the smooth running of the school negatively since it affects delivery of the curriculum and incomplete syllabus coverage. Again there was disciplinary problems and unnecessary tension between the teachers who are always present at school and those frequently absent. It was recommended that Free state department of education should ensure that they hold policy management workshops to stop the scourge of habitual absenteeism, (Mothibeli 2017). The author did not show the population of the study and the sampling technique adopted.

In the same perspective, in Montgomery, Alabama, Brown, \& Arnell (2012) looked at measuring the effect teacher absenteeism has on student achievement at an urban but not too urban title 1 elementary school. The objective was to address the effects of teacher's absenteeism on academic achievement in grade 3-6 in a selected elementary school in Montgomery, Alabama. Sat 10 score and spread sheet were used to show the relationship between students performance.
Descriptive statistics (frequency, percentage, means, and standard deviation) was used in analyzing data, Alabama, Brown, and (Arnell 2012). Similarly, it is in tandem with the present study because they are both on effects of absenteeism. The variation was that the previous study was on student's achievement while the present will be on teachers absenteeism in Osadenis mixed secondary school Asaba, Delta state, Nigeria. The piece, when taken as a whole, is relevant and very convincing in theory but starts slow and never laid out a concrete way of approaching this complex problem.

Stretching further, the article written by Obiero, Mwebi \& Nyang'ara (2017) and titled factors influencing teacher absenteeism in public secondary schools in Borabu sub-country, Kenya. The objective was to examine the influence of selected personal characteristics (teachers' age, gender, marital status and educational qualification) on teacher absenteeism in public secondary schools in Borabu sub-country Kenya. The study adopted ex-post facto research method. A population of 245 teachers and 21 school principals in public secondary schools in Borabu sub country A sample of 152 teachers were selected using stratified random sampling and purposive sampling was used in selecting 20 school principals. SPSS and ANOVA were used for data analysis. The findings revealed that illness of teachers or close family members was the most common reason causing teacher absenteeism, most principals held the perception that female teachers had higher rate of absenteeism than their male 
counterparts although teachers gender did not have a significant influence on teacher absenteeism. It recommends sensitization workshop and seminars to eliminate negative perception of principals about female teachers and introduction of biometric attendance register to curb absenteeism, (Obiero, Mwebi \& Nyang'ara 2017). The previous study was foreign while the present study will be local with emphasis on Osadenis mixed secondary school, Asaba, Delta State, Nigeria. While the study has merit, the methods need to be re-evaluated. The power of the study needs to be created by obtaining a larger sample size.

In a related study captioned relationships between teacher attendance and student scores on the tennessee comprehensive assessment program achievement test in East Tennessee and authored by Hensley \& Hope (2011). The goal was to examine relationship between third, fourth and fifth grade teacher attendance as well as teacher and administrator perceptions of teacher attendance during the 2005-06, 2006-07 and 2007-08 school years. Third, fourth and fifth grade student test scores on the Tennessee comprehensive assessment programme (TCAP) achievement test given in the spring of 2006, 2007 and 2008 were also examined. TCAP score data were electronically gathered and interview was used. The population comprised of five K-5 schools and two K-8 schools in a small, rural, public school system in Tennessee. Quantitative data were analyzed using t-test and ANOVA. Findings revealed that teachers and administrators who participated in this study agreed that teacher absences do affect student test scores, but the quantitative data did not support this, (Hensley \& Hope 2011). The difference was that the previous study focused on student scores, used ANOVA while the present study will use means scores of the responses. The study did not show the population of the study and techniques used in the study. That made it difficult to generalize the findings.

\section{Gap in Literature}

The reviewed literature pointed out that researchers have investigated the broad teachers' absenteeism. Most of the studies were foreign based but few related local studies were found to focus elsewhere. None focused on Osadeni's mixed secondary school Asaba Delta state. However, the inadequacies, incompleteness and incommensurability the current literature has not addressed created the yawning knowledge gap the study will fill.

\section{Hypothesis}

- There is no significant relationship between the use of electronic register and teacher's absenteeism in Osadeni's Mixed Secondary Schools Asaba, Delta State.

\section{Theoretical Consideration}

Behavioural change theory was adopted as the theoretical umbrella for this discourse. It is a seminal theory used in diverse fields of study to explain changes in human behavior. The major proponents of the theory are Icek Ajzen 1985, Madden, 1986. It entails that behavior depends on one's intention to perform the behavior. Intention is determined by a person's attitude (belief and values of the outcome of the behavior and subjective norms (beliefs 
about what other people think the person should do of social pressure). It could also depend on someone's ability to perform depending on the situation, (World Bank 2018). Similarly, the theory of planned behavior connotes that change in awareness and intention leads to action. Attitudes, social norms and perceived control are the offshoot of intentions and behavior of people, (Prager 2012).

In the same perspective, theory of planned behavior means that intention is directly determined by three factors: subjective norm, attitude of a person and behavior control factor; The theory is relevant to this study because it helps in studying and learning how and what influences a person's behavior such as teachers' absenteeism to work in order to create a change of such individual, (Ghouril, Khanl \& Kareem, 2016).

\section{Tenets of Behavioural Change Theory}

The tenets of theory of planned behavior are: (1) Nobody is in control of actual performance of a behavior (2) Behaviour influenced by conscious thought. (3) Self efficacy (4) There is fear (5) Threat also exist (6) There must be barriers (7) There will be benefits after the change (8) This will lead to the display of attitude (9) The intention the individual behind the action takes (10) and reluctance to do something.

\section{Application of the Theory to the Study}

Behavioural change theory is relevant to the study because it has been lauded as the most influential in the study of absenteeism. Consequently, behavior change takes place when someone is faced with a familiar condition and something new or different happens quickly, (Ran dolf 2018). Laying credence to that, most behaviour of absenteeism embarked upon by teachers in schools are based on what they had always done previously. That behaviour of absenteeism continued to serve the institution in the past until the Delta state government thought of the menace overtime and took a decision to change the situation via the intention of applying electronic register to eliminate teachers' absenteeism, ("Behavioural change theory," (n.d.). The intentions or decisions to make a change were either translated to a successful behavioural change or they never resulted to actual behavior change. However, the use electronic register predicted the outcome of the study which translated to a reduction of teachers' absenteeism on institutional culture, extracurricular activities, workplace abuse, poor supervision of attendance, poor control of the principal, burn out of teacher among others, (Ogden, Karim, Choudy \& Brown 2007). 
Figure 1: Diagram Showing the Application of Theory of Planned Behaviour to Effects of Electronic Register on Teachers' Absenteeism in Osadeni's Mixed Secondary School, Delta State.

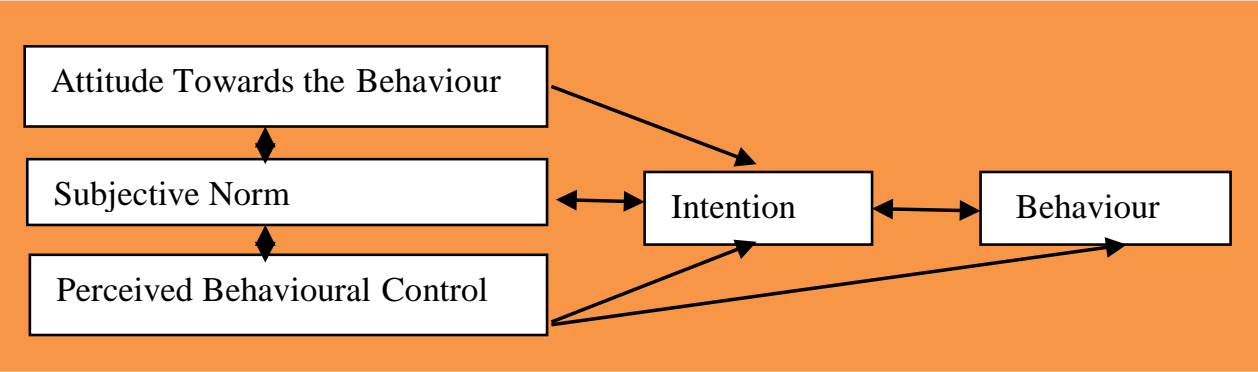

Source: Adapted from World Bank. (2018). Theories of behaviour change, DFID: Communication for governance and accountability programme. Retrieved from www.google.com.ng.

The above table revealed that a successful execution of behaviour of absenteeism to work by teachers was traceable to the formation of an intention, course of an action or goal behind the action. Such intention to absent from work was determined by the attitude and feelings of teachers' or subjective norms (that which is regarded as normal, like permission, prohibition or school culture). The behaviour of absenteeism resulted to an outcome leading to disruption and ineffective instruction given to students, inefficiency and low productivity of teachers'. It was that belief that led to the attitude of absenteeism of teachers from work. In order to take care of such behaviours that need individual attention, perceived behavioural control becomes very essential. It means that, individuals understanding of their capacity or ability to put into practice a particular behaviour in order to have self control (Ghouril, Khanl \& Kareem 2016).
It was in that direction, that the Government introduced the automated electronic register to monitor teachers for accurate and timely attendance. It was expected that it will bring a paradigm shift from the culture of absenteeism to spirit or behaviour of punctuality and timely attendance to work in order to improve productivity and reduce disruption and ineffective instruction to students.

\section{Research Methodology Method of study}

To ensure an effective research, the study adopted a survey method. Simple random sampling method was used

Population Size, Sample Size and Sampling Procedure

The study was a survey research. Simple random sampling procedure was used because each respondent has the equal opportunity of being selected. The total population of the study is 102 (one hundred and two), ("Monthly returns of Osadenis staff strength" 2019). The sample size of 29 was generated using Taro Yamen's formula $\mathrm{S}=\mathrm{N} /(1+\mathrm{N} \alpha 2)$ 
of 1973 and a self administered questionnaire was distributed proportionately among the teaching staff of Osadeni's mixed secondary school. The following table illustrates the sample procedure.

Table 1: Sample Procedure

\begin{tabular}{|c|c|c|c|}
\hline Category of Staff & Population Size & $(\boldsymbol{\%})$ Size & Sample Size Proportion \\
\hline GRADUATES & 81 & $79 \%$ & 23 \\
\hline HND & 6 & $6 \%$ & 2 \\
\hline NCE & 15 & $15 \%$ & 4 \\
\hline TOTAL & 102 & $100 \%$ & 29 \\
\hline
\end{tabular}

Source: Authors Field Survey (2020).

\section{Method of Data Collection}

In gathering data for this study, primary and secondary sources of data will be employed. The face-to-face interview conducted by the researcher on the teaching staff and a self administered questionnaire will be used to complement the secondary source largely adopted from journals, textbooks, newspapers and government documents.

\section{Method of Data Analysis}

Data will be analyzed using quantitative method. A five point Likert scale was used. Data will be analyzed using mean item and percentages.

\section{Data Presentation and Analyses}

The result of the study was presented bearing in mind the objective. It revealed the following:

Table 2: Percentage, Decision and Mean Scores of Respondents on Whether the Use of Electronic Register has Reduced Teachers Absenteeism from Work on the following:

\begin{tabular}{|c|c|c|c|c|c|c|c|c|}
\hline $\mathbf{S} / \mathbf{N}$ & ITEMS & SA (5) & $\mathbf{A}(4)$ & UD(3) & $\mathbf{D}(2)$ & SD(1) & MEAN & DECISION \\
\hline 1 & Institutional culture & $8(28 \%)$ & $17(59 \%)$ & $0(0 \%)$ & $3(10 \%)$ & $1(3 \%)$ & 3.96 & Accepted \\
\hline 2 & $\begin{array}{l}\text { Extracurricular } \\
\text { activities }\end{array}$ & $4(14 \%)$ & $\begin{array}{c}9 \\
(31 \%)\end{array}$ & $\begin{array}{c}4 \\
(14 \%)\end{array}$ & $\begin{array}{c}10 \\
(34 \%)\end{array}$ & $\begin{array}{c}2 \\
(7 \%)\end{array}$ & 3.10 & Accepted \\
\hline 3 & Work place abuse & $6(21 \%)$ & $11(38 \%)$ & $3(10 \%)$ & $7(24 \%)$ & $2(7 \%)$ & 3.41 & Accepted \\
\hline 4 & $\begin{array}{l}\text { Poor supervision of } \\
\text { attendance }\end{array}$ & $\begin{array}{c}9 \\
(31 \%) \\
\end{array}$ & $\begin{array}{c}7 \\
(24 \%) \\
\end{array}$ & $\begin{array}{c}1 \\
(4 \%) \\
\end{array}$ & $\begin{array}{c}9 \\
(31 \%) \\
\end{array}$ & $\begin{array}{c}3 \\
(10 \%) \\
\end{array}$ & 3.34 & Accepted \\
\hline 5 & $\begin{array}{l}\text { Poor control of the } \\
\text { principal }\end{array}$ & $\begin{array}{l}6 \\
(21 \%)\end{array}$ & $\begin{array}{c}7 \\
(24 \%) \\
\end{array}$ & $\begin{array}{c}5 \\
(17 \%)\end{array}$ & $\begin{array}{c}8 \\
(28 \%) \\
\end{array}$ & $\begin{array}{c}3 \\
(10 \%) \\
\end{array}$ & 3.17 & Accepted \\
\hline 6 & $\begin{array}{l}\text { Burn out as age of } \\
\text { teachers increase }\end{array}$ & $6(21 \%)$ & $7(24 \%)$ & $9(31 \%)$ & $5(17 \%)$ & $2(7 \%)$ & 3.34 & Accepted \\
\hline 7 & Family responsibility & $1(4 \%)$ & $12(41 \%)$ & $2(7 \%)$ & $11(38 \%)$ & $3(10 \%)$ & 2.89 & Rejected \\
\hline 8 & Personal illness & $2(7 \%)$ & $12(41 \%)$ & $2(7 \%)$ & $11(38 \%)$ & $2(7 \%)$ & 3.03 & Accepted \\
\hline 9 & High work load & $2(7 \%)$ & $4(14 \%)$ & $5(17 \%)$ & $14(48 \%)$ & $4(14 \%)$ & 2.51 & Rejected \\
\hline 10 & Job dissatisfaction & $3(10 \%)$ & $8(28 \%)$ & $3(10 \%)$ & $11(38 \%)$ & $4(14 \%)$ & 2.82 & Rejected \\
\hline 11 & $\begin{array}{l}\text { Ineffective monitoring } \\
\text { of work attendance }\end{array}$ & $7(24 \%)$ & $9(31 \%)$ & $1(4 \%)$ & $8(27 \%)$ & $4(14 \%)$ & 3.24 & Accepted \\
\hline \multirow[t]{3}{*}{12} & Death in the family & $3(10 \%)$ & $5(17 \%)$ & $6(21 \%)$ & $4(14 \%)$ & $11(38 \%)$ & 2.48 & Rejected \\
\hline & Total & 57 & 108 & 41 & 101 & 41 & 37.29 & Accepted \\
\hline & Grand Mean & & & & & & 3.10 & Accepted \\
\hline
\end{tabular}

Source: Authors Field Work, (2020). 
$\operatorname{Mean}(\overline{\mathrm{X}})=\frac{\sum f x}{N}$

Data on Table 2: showed that items 1,2, $3,4,5,6,8$ and 11 had mean scores above the criterion mean of 3.0. This indicated that the use of electronic register has reduced teachers' absenteeism from work. The other items 7, 9, 10 and 12 had mean score below the criterion mean of 3.0. The grand mean (3.10) was above the criterion mean, which showed that the use of electronic register has reduced teachers' absenteeism from work and was therefore accepted.

\section{Findings and Discussion}

The study revealed that the paradigm shift from use of manual register to electronic register, eradicated the culture and tradition of the community. The study established that there was a reduction on the idea of some teachers who formed the habit of absenting themselves from work for about one to three months. This is usually common at the demise of a husband or relation as the culture and tradition of their community demands at the detriment of their job. Such menace was addressed because the worker must clock in and out of work through thumb printing. (W. Nwobi, personal communication, January 15,2020$)$. In the same manner, Table 2: item 1 indicates that a greater percentage of the respondents agreed that there was reduction on absenteeism in relation to institutional culture as the following statistics revealed (28\% SA, $59 \% \mathrm{~A}, 0 \% \mathrm{U}, 10 \% \mathrm{D}$ and $3 \% \mathrm{SD}$. Mean=3.96).

In the same manner, the result on Table 2: item 2 also revealed that the percentage and mean score on absenteeism as it concerns extracurricular activities was accepted as follows: $(14 \% \mathrm{SA}, 31 \% \mathrm{~A}, 14 \% \mathrm{U}$, $34 \% \mathrm{D}$ and $7 \%$ SD. Mean=3.10). The grand mean was accepted because it was above the criterion mean.

Again, it was also evident that from the interview response that initially, workers' will go to work and sign in for several friends who may end up not going to work. Since the introduction of the electronic register, such undue practices are no longer tenable because finger prints differ. Ghost workers who are resident in other states of the nation but claim to be staff of Delta state were easily discovered because the automated electronic device has the bio data of all the staff. It alleviated the fright of some workers' going the same time to clockin and clock-out (G. Nwobi, personal communication, January 15, 2020). Furthermore, statistically from Table 2: item 3, the percentage of absenteeism on workplace abuse was reduced as shown below (21\% SA, 38\% A, $10 \% \mathrm{U}$, $24 \%$ D and 7\% SD. Mean=3.41).

Previously, the absence of supervision and inspection of schools could have accounted in part for the seemingly high cost of absenteeism among school teachers, (Mothibele 2017). However, the use of electronic register also revealed on Table 2: item 4, (31\% SA, $24 \% \mathrm{~A}, 4 \% \mathrm{U}, 31 \% \mathrm{D}$ and $10 \% \mathrm{SD}$. Mean=3.34), that there was reduction on the number of teachers' who absent from work without genuine reasons and official permission as statistics on the

URL: http://journals.covenantuniversity.edu.ng/index.php/cjbss 
table revealed. That led to improved production and quality of work. Poor performance of teachers was reduced.

In the same perspective, the study showed that most of the ghost workers no longer find it easy because of the use of thump print of workers during clocking -in and clocking-out of work. The unions (Nigerian Union of Teachers) have been the beneficiary of ghost workers over the years. This is because the unions connive with the ghost workers who agree to pay them a certain percentage of their salary on monthly basis. Besides, F. Akpata (personal communication, January 15, 2020), maintained that dead workers whose names were still on the payroll of Delta State government were discovered.

Regarding poor control of principal, the Vice - principal administration at present, should be aware of staff absenteeism to work. He is supposed to send a letter written by the teacher with reasons for being absent to work to Hekerbella (the company in charge of the electronic register). There is also a manual attendance register for teachers which eventually are submitted to post primary education board (G. Nwobi, personal communication, January 15, 2020). That was in tandem with the result on Table 2: item 5 that revealed the percentage and mean score of respondent that accepted as follows: (21\% SA, $24 \%$ A, $17 \%$ U, $28 \%$ D and $10 \%$ SD. Mean=3.17). In other words, there was reduction on absenteeism through adequate control of teachers by the principal. The same evidence was established by Musyoki (2015) who said that monitoring of teachers by the principal accompanied by disciplinary action, use of camera, regular assessment by Quality Assurance Standard officers and assessment by Ministry officials also reduced absenteeism.

It was evident from the study that, the excuses of burnout as the age of the teacher increased was taken care of. This was because teachers joined the teaching profession when they were highly motivated but they burnout as the age of the teacher increases (Glewe \& Kremer, 2006). Similarly, prolonged related stress, within employees who have face-to-face with people from other portfolio also translates to absence from work as a result of overload or long hours devoid of rest, (Badubi 2017). In the same context, Table 2 : item 6 result aligned with the above submission that there was improvement as statistically shown below (21\% SA, $24 \% \mathrm{~A}, 31 \% \mathrm{U}, 17 \% \mathrm{D}$ and $7 \% \mathrm{SD}$. Mean=3.34). Besides, workers who lacked the zeal to perform either resigned or were forced by the use of electronic register to become active again via being punctual to work.

In the same direction, the machine gave the employer an opportunity to ascertain the actual number of employees in the institution. Amidst that, it helped to ascertain the actual time an employee resumes duty. In situations where time factor is taken into consideration in the payment of salary, the clocking machine will aid the employers of labour to calculate workers salaries based on the number of hours put in at work (K. Idi, personal communication, January 15 , 2020). In the same context, it has helped to enforce punctuality unlike the era of

URL: http://journals.covenantuniversity.edu.ng/index.php/cjbss 
manual attendance list where employees forged the dates and time of arrival to work. Furthermore, it led to a transformation from the previous manual transcribing of data which was capital intensive to the era of biometric register that significantly reduced time and attendance fraud. That reduced the labour and capital intensive nature of manual attendance and other pranks played by employees, (Kronos 2017).

Following that, absenteeism on family responsibility is linked to the statistical data on Table 2: item 7, as indicated below (4\% SA, $41 \%$ A, $7 \%$ UD, 38\% D and $10 \%$ SD. Mean=2.89). The mean score was indicative of the fact that teachers' absenteeism did not reduced on family responsibility. Again, the percentage of respondents that disagreed was minimal. According to Erickson, Nichols \& Ritter (2000) family responsibilities should not have direct effects but rather moderates the effect of attendance motivation on absenteeism. In other words, family responsibilities can't contribute directly to increased absenteeism but are mediated by whether such demands are perceived as being stressful or harmful to the family well-being in other ways. However, the emotional well-being of one's family life could spill over to affect one's work life.

Besides, the study showed that even in an event of sickness, the teacher must struggle to be present at work unlike what it was before the introduction of electronic register (U. Ayare, personal communication, January 15,2020$)$. That was in agreement with the result on Table 2: Item 8 which revealed that a greater percentage of the respondents agreed that the use of electronic register has reduced teachers' absenteeism from work on personal illness as revealed on Table 2: item 8, as follows: (7\% SA, $41 \% \mathrm{~A}, 7 \% \mathrm{U}, 38 \% \mathrm{D}$ and $10 \% \mathrm{SD}$. Mean=3.03). The mean score was above the criterion mean which signified accepted. Similarly, employees no longer use sickness as an excuse to absent from work because no matter how severe an illness is, the employee will strive to clock in and out of work. Electronic register has reduced employee absenteeism on lateness, abuse of time, commitment to duty and discipline (K. Agwemmoria, personal communication, January 15, 2020).

In consonance with the above view, the colleagues of the absentee's meant to stand for their absent co-workers are no longer subjected under increased pressure and stress. For instance the rate of substituting teachers has reduced and they measure up to the regular classroom teacher's routine and methods to stimulate students to learn. Teachers no longer attract excess workload because they want to substitute an absentee. By and large, the use of electronic register reduced absenteeism on adequate supervision (Badubi, 2017). In the same context, Obiero, Mwebi, \& Nyang'ara (2017), submit that excessive workload should not be a reason for absenting from school. Therefore majority of the respondents from Table 2, item 9, depict as follows; (7\% SA, $14 \%$ A, $17 \% \mathrm{U}, 48 \% \mathrm{D}$ and $14 \% \mathrm{SD}$. Mean=2.51). The grand mean was rejected because it was less than the criterion mean of 2.5. In the same perspective, Augustine (2020) concurred that, even teachers who

URL: http://journals.covenantuniversity.edu.ng/index.php/cjbss 
feigned their retirement age in order to stay longer and become unproductive while complaining about workload would be exposed.

In the light of absenteeism on Job dissatisfaction represented as Table 2: item 10, showed below: (10\% SA, $28 \%$ A, $10 \%$ UD, $38 \%$ D, $14 \%$ SD. Mean=2.82). It was evident that teachers' absenteeism was not reduced because the mean score was below the benchmark of 2.5 and a smaller percentage of the respondents were negative in their response. That was why Blau (1985) depicts that non professional teacher's use the teaching profession as a stepping stone in life. Therefore they chose to teach but as soon as they get something they prefer, they quit the teaching job. Ejere (2010) confirmed the above summation by saying that teachers' absent themselves from school as a result of wanting to leave the profession they are engaged in when it becomes unattractive to them. However, the deep rooted dissatisfaction with their job emanated from their poor condition of service and low career prospects.

In a similar context, the respondents perceptions as shown on Table 2: item 11, revealed the following: (24\% SA, $31 \%$ A, $4 \%$ UD, $27 \%$ D \& $14 \%$ SD. Mean=3.24). It was evident from the foregoing that there was a decrease on teachers' absenteeism in relation to ineffective monitoring of work attendance. That was because the mean score was higher than the benchmark of 2.5 required and the percentage of respondents response was also higher.

In view of Table 2: item 12 above, the percentage representation of the result is as follows: (10\% SA, $17 \% \mathrm{~A}, 21 \% \mathrm{UD}$, $14 \% \mathrm{D}, 38 \%$ SD. Mean=2.48). It was obvious that the mean score was below the criterion mean which was rejected. Death is a natural thing that awaits everybody. Therefore in an event of death, teachers are usually allowed to take some time off work to attend to the burial. In corroboration of the above view, "Missing work due to death," (n.d.) posited that in an event of the death of a loved one, the affected person often loses focus. His/her attention will be directed towards home and seeking for ways to deal with the grief. On account of that, the worker reserves the statutory right to a "reasonable" amount of unpaid time off in line with Employment Rights Act to allow them to deal with unforeseen matters and emergencies involving a dependant, (Landau 2014).

Furthermore, it puts a check on time theft and buddy punching that assists the organisation to maximise cost. In the same vein, N. Ethele (personal communication, January 15, 2020), further explained that workers are now punctual to work unlike before when workers absent themselves from work as they wanted without due process.

In as much as there is improvement on teachers absenteeism, the electronic register is faced with some challenges which includes it malfunctions most time (P. Marah, personal communication, January 15, 2020). This is as a result of network fluctuation from time to time. Again, there is lack of constant electricity to power the machine and lack of experts to manage and maintain the device. This can cause the information on it to be wiped off if 
not properly maintained (N. Ethele, personal communication, January 15, 2020). Despite that, the machine breaks down occasionally because of network failure (T. Ntoka, personal communication, January 15, 2020). In an event of network fluctuation, clocking in and out are delayed. Teachers whose classes are on first period could have their lessons affected while waiting to clock in (K. Agwemmoria, personal communication, January 15, 2020). More so, some teachers see it as a painful process since they have to wait after several attempts to clock in and out of work.

\section{Concluding Remarks}

The principal conclusion to draw from this study is that the use of electronic register has greatly reduced the rate of absenteeism to work. As such, it, led to reduction of ghost workers because of the need to thumb print while clocking in and out of work. School heads also take supervision serious. Again, the productivity of teachers improved. Similarly, the idea of using the death of a relative as excuse to absent for months was eradicated. It suffices to say that for efficiency and effectiveness at work, the following recommendation should be applied to strengthen and pull the institutions out of the quagmire of absenteeism from work.

\section{Recommendations}

The study recommends the following:

\section{References}

Activities of the commission and it's achievements since inception of the present administration (2017).
1. There should be reasonable deduction in the salary of any teacher who absent from work without an acceptable reason and permission.

2. Wage payment should be dependent on production quality. If teachers are aware that their salaries are to be affected negatively, they will bring out their best and desist from absenteeism.

3. The school management should implement incentive programme to encourage and reward good attendance. This could be achieved through giving of monetary bonus to teachers whose attendances are unquestionable.

4. Principals need to explain attendance expectations to faculty and staff at the beginning of each school year and then follow up to monitor attendance of workers.

5. The functions of the machine have to be improved. To achieve this, there should be constant supply of electricity to power the machine and provision of trained experts to manage and maintain the device. This will help in sustaining the data on it.

6. The school authority should put teachers' attendance data on students' report card. If teachers know that the students will make mockery of them, they will bring out their best and reduce the rate of absenteeism.

Retrievedfromhttp://www.deltasta te.gov.ng.

Augustine, O. (2020).Transfers, absenteeism and headache for 
teachers.

Retrieved

fromhttp://www.standardmedia.c o.ke.

Australasian Faculty of Occupational Medicine (1999). Workplace attendance and absenteeism. Australia. A report prepared by the Australasian faculty of occupational medicine. Sydney N. S. W: Royal Australian college of http://www.trove.nla.gov.au.

physicians.

Badubi, R. M. (2017) A critical risk analysis of absenteeism in the work place. Journal of International Business Research and Marketing, 2(6), 32-36.

Behavioural change theory. (n.d.) http://www.lshtm.ac.uk.

Bhatia, S. K. (1981). Management of Absenteeism. New Delhi: Asian Publication Services.

Blau, G. J. (1985) Source-related determinations of perceived job scope. Human Communication Research, 11(4), 536-553.

Brown, S. L. \& Arnell, A. T. (2012) Measuring the effect teacher absenteeism has on student achievement at a urban but not too urban title 1 elementary school. International Journal of Humanities and Social Sciences, 2(17), 172-183.

Dafiaghor, F. K. (2011). Lateness: A Major Problem Confronting School Administrators in Delta State. International NGO Journal, 6(7), 166-169.

Ejere, E I. (2010) Absence from work: A study of teacher absenteeism in selected public primary schools in Uyo, Nigeria. International
Journal of Business and Management, 5(9), 115-123.

Erickson. R. J. Nichols, L. \& Ritter, C. (2000) Family influences on absenteeism: Testing an expanded process model. Journal of Vocational Behavior, 57, 246272.

Ghouril, A. M. Khanl, N. \& Kareem, A (2016) Improving employee's behaviour through extension in theory of planned behaviour: A theoretical perspective for SMEs. International Journal of Business and Management, 11(11), 196213.

Glewwe, P. \& Kremer, M. (2006). Schools, teachers and education outcomes in developing countries. Handbook of the economics of Education. Retrieved from https://www.isid.ac.in/ tridip/teac hing/developmentmicroeconomic s/spring2012/readings/04educatio n/04Glewwe\&Kremerhandbooko feconomicsofeducation2006.pdf.d oi:10.1016/S15740692(06)02016-

Hensley, M. \& Hope, M. (2011).Relationships between teacher attendance and student scores on the Tennessee comprehensive assessment program achievement test in East Tennessee. (Unpublished d0ctoral dissertation).East Tennessee State University, Southern region: U.S.A.

Hornby, A. S. (Ed). (2015) Oxford advanced learners dictionary (8th ed.). New York: Oxford University Press. 
Ivory, P. (2016). Clocking in system: The benefits and advantages. Retrieved from https://advancesystems.ie/theadvantages-and-benefits-ofusing-a-clock-in-machine.

Jethro-Ibileke, (2017). Delta introduces electronic register for LG workers. Retrieved from $\mathrm{http} / \mathrm{www} \cdot$ thenewsnigeria.com.

Kronos, (2017). Detecting a widespread but hidden business cost: Time theft.

Retrievedfromhttp://www.kronos. com.

Landau, P. (2014). Bereavement leave: your rights in seeking support at work.

Retrieved fromhttps://www.theguardian.co $\mathrm{m} /$ money/workblog/2014/jan/10/bereavementleave-your-rights-support-work.

Markussen, S. Roed, K. Rogeberg, O. J. \& Gaure, S. (2009) The Anatomy of Absenteeism. Norway: The Ragnar Frisch Centre for Economic Research.

Mgonja, M. G. (2017) Responding to workplace absenteeism in Tanzania: The case of public and private schools in Ilala Municipal and Mkuranga District. International Journal of Educational Leadership and Management, 5(1), 85-108.

Mikhaylov, A. (2019). What is biometric attendance system? Retrieved from http://www.quora.com.

Missing work due to death: Rules of Bereavement, (n.d.).Retrieved from

https://thedisabilityguys.com/miss ing-work-due-to-death-rules-ofbereavement/

Mogobe, T. H. (2011). Guidelines for development: An absenteeism management programme within an institution for higher learning. (Master's thesis, University of Pretoria, Gauteng: South Africa). http://www.repositary.up.ac.za.

Morris, J. Marzano, M. Dandy, N. \& O'Brien, L. (2012) Theories and models of behavior and behavior change: Foresty, sustainability, behaviors and behavior change: Theories: forest research.

Mothibeli, T. R. (2017). The causes and effects of uncontrolled teacher absenteeism in selected public primary schools in Mangaung metro municipality (Bloemfontein). (Unpublished master's thesis). Central University of Technology: Free State.

Musyoki (2015). Key factors influencing teacher absenteeism in public secondary schools in Nzauisub county Makueni county. (Master's thesis, Southern Eastern Kenya University, Kenya). http://www.repository.seku.ac.ke. Naughten, D. (2015). A Study of Absenteeism within Company X, its Causes and the Management of it. (Unpublished Bachelor of Arts thesis). National College: Ireland.

Niemeyer, B. (2013). Examining the Effect of Teacher and Student Absence on Elementary Student Proficiency.

(Unpublished 
doctoral dissertation) Drake University: Des Moines, Iowa.

Obiero, E. O. Mwebi, B. R. \& Nyang'ara N. M. (2017) Factors influencing teacher absenteeism in public secondary schools in Borabu sub-country,Kenya. International Journal of Education and Research, 5(7), 123-138.

Obong-Denteh, W. (2011) Impact of student and teacher absenteeism on students' performance at the junior high school: The case of the Kumasi-Metro school district. Continental Journal of Education Research, 4(1), 7-17.

Ogden, J. Karim, L. Choudy, A. \& Brown, K. (2007) Understanding successful behavior change: The role of intentions, attitudes to the target and motivation and the example of diet. Health Education Research, 22(3), 397-405.

Monthly returns of Osadenis staff strength. (2019). Osadenis mixed secondary school Asaba, Delta State Nigeria: Bursar.

Osahor, P. (2017). Commencement of electronic attendance register for staff of Delta state unified local government service and local government education authorities. Retrieved from https://www.deltastate.gov.ng/co mmencement-of-electronicattendance-register.

Prager, K. (2012) Understanding Behavior Change: How to Apply Theories of Behavior Change to SEWeb and Related Public
Engagement Activities. United kingdom: James Hutton Institute. Ran dolf, E. (2018). Tackling teachers' absenteeism with the theory model. http://www.shared.rti.org.

Robinson, M. C. (2008) Teacher absenteeism: Its relationship to students' performance on states assessments in English language arts grades three, five and seven. (Doctoral dissertation, St John Fishers College, NY: Rochester, U.S.A.).Retrievedfrom http//www.fisherpub.sjfc.edu/edu cation_etd/83.

Sende, J. (2000). Schools that Learn. New York: Doubleday Publishing Group.

The Citizen Newspaper (2018). Delta state begins automated register for staff attendance. Retrieved from

http//www.thecitizenng.com.

Ugoani, J. N. (2016) Education corruption and teacher absenteeism in Nigeria. International Journal of Management and Production, 7(2), 1-15.

Waldron, J. (2008). Who is a teacher? Retrievedfromhttp//:www/billards .colostate.edu.pbreview.

Wikibooks, (2017). Digital electronic register.Retrievedfromhttp//:www .en.wikibooks.og.

World Bank. (2018). Theories of behaviour change, DFID: Communication for governance and accountability programme. Retrieved from www.google.com.ng. 